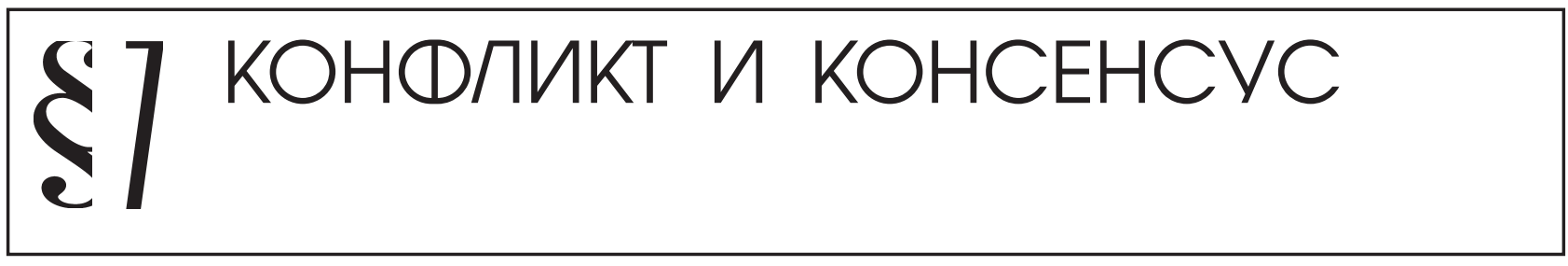

И.В. Григорян

\title{
ПОЛИТИЧЕСКИЙ КУРС ТУРЦИИ В ОТНОШЕНИИ ПОСТСОВЕТСКИХ ГОСУДАРСТВ НА ЮЖНОМ КАВКАЗЕ (1991-2008 гг.)
}

Аннотация: В настоящей статье представлены результаты анализа внешней политики Туричии на Южном Кавказе в период с 1991 по 2008 г2. - в отношении Армении, Азербайджана, Грузии, возникиих в результате распада СССР и традиционно входящих в зону политического влияния России. Отмечается, что в связи с распадом СССР Туричия стала поводить на Южном Кавказе активную внешнюю политику, стремясь вовлечь молодые государства в сферу своего влияния и ослабить позиции России. Сегодня Туричи рассматривает Южный Кавказ как сферу своих национальных интересов, что не может не идти в разрез с интересами России.

Ключевые слова: Политология, политика, Южный Кавказ, Турция, внешняя политика, международные отношения, конфликт, Россия, региональная безопасность, геополитика

Ю жный Кавказ - часть Кавказа, лежащая к югу от Главного, или Водораздельного, хребта Большого Кавказа. К Закавказью относятся большая часть южного склона Большого Кавказа, Колхидская низменность и Куринская впадина, Малый Кавказ, Джавахетско-Армянское нагорье, Талышские горы с Ленкоранской низменностью. В последние годы в международных документах для обозначения Закавказья распространение получил термин «Южный Кавказ» ${ }^{1}$.

Южный Кавказ, - важный геополитический регион, с глубокой древности, представлявший связующее звено между странами Востока и Запада и находившийся на перекрёстке торговых путей между Ближним и Средним Востоком и Европой, миграционных волн, армий завоевателей, стремившихся овладеть древними и средневековыми государствами Закавказья². Широки были торговые и культурные связи этих государств между собой и с сопредельными странами Европы и Востока ${ }^{3}$. В пределах Закавказья расположены основные части Грузии, Азербайджана и Армении.

\footnotetext{
${ }^{1}$ http://ethnomir.ru/ethno/caucasus

${ }^{2}$ KavkazWeb.net - Главный интернет портал Кавказа

${ }^{3}$ Редакционная коллегия. Закавказье и сопредельные страны в период эллинизма./История Древнего мира. Расцвет Древних обществ.- М.:Знание, 1983 - с.399-414
}

Армения - страна в Закавказье, не имеющая выхода к морю. Расположена на северо-западе Армянского нагорья, называемого исторической Арменией, между Чёрным и Каспийским морями. С севера и востока обрамлена хребтами Малого Кавказа. Граничит с Грузией, Азербайджаном, Ираном и Турцией. Несмотря на то, что географически Армения расположена в Азии, она имеет тесные политические и культурные связи с Европой. Армения всегда находилась на перекрёстке путей, соединяющих Европу и Азию, поэтому её рассматривают в качестве трансконтинентального государства ${ }^{4}$.

Грузия - государство в центральной и западной части Закавказья на юго-восточном побережье Чёрного моря. Граничит с Россией на севере, Азербайджаном на юго-востоке, Арменией и Турцией на юге.

Азербайджан - государство в восточной части Закавказья (Южного Кавказа), на юго-западном побережье Каспийского моря. Граничит с Россией (Дагестан) и Грузией на севере, Арменией на западе и Ираном на юге. Нахичеванская Автономная Республика - эксклав Азербайджана - граничит с Арменией, Ираном и Турцией ${ }^{5}$.

Анализ геополитической ситуации в регионе проводится по следующим критериям:

\footnotetext{
${ }^{4}$ www.abp.am>armenia/geo

${ }^{5}$ http://ru.wikipedia.org/wiki/A3ep6aitfl>KaH
} 
Конфликт и консенсус

- определение сильных и слабых сторон одних государств региона по отношению к другим государствам, определение соперников и союзников избранного а качестве объекта анализа государства, его соседей, а также глобальных и региональных держав, имеющих к ним отношение;

- оценка того, являются эти слабые и сильные стороны, сопернические отношения и союзы стабильными или способны изменяться;

- определение того, какие последствия будут иметь изменения в любых из этих элементов для существующих сопернических и союзнических отношений данной страны ${ }^{6}$.

У Азербайджана есть пять важных геополитических вопросов: нефтепроводы, раздел Каспийского моря, Нагорный Карабах, Южный Азербайджан, демократизация.

У Грузии: напряженные отношения с Россией, военный конфликт с Южной Осетией, транзитный потенциал страны, вопрос вступления в НАТО.

У Армении: блокада со стороны Турции ${ }^{7}$ и Азербайджана, изолированность от региональных проектов, Нагорный Карабах, признание вопроса геноцида армян в Османской Турции.

Указанные вопросы нельзя рассматривать отдельно от вопросов геополитического значения региона для сопредельных с этим регионом стран, таких как Турция, Россия и Иран и других заинтересованных стран - США и ЕС.

Геополитическое значение кавказского региона для Ирана и Турции трудно переоценить ${ }^{8}$. Достаточно указать на тот факт, что до начала XX века отдельные части Кавказа либо непосредственно входили в состав Османской империи и Персии, либо являлись их ближней периферией. Многие народы Кавказа имеют в Иране и Турции либо территории, идентифицируемые в качестве этнических либо исторических территорий, либо более или менее многочисленные диаспоры, оказывающие, в прямой или опосредованной форме, влияние на внешнюю и внутреннюю политику Анкары и Те-

6 Каи М. Геополитика Азербайджана/ Кац М. //United Press International.- США .-2006.-22 августа

${ }^{7}$ В 1993 году Турция в одностороннем порядке блокировала армяно-турецкую границу, официально мотивируя это оккупацией азербайджанских районов армянскими войсками.

8 Андрей Арешев, Турция, Иран и Россия в Закавказье, 26.11.2010 герана9 . Поэтому вполне естественно, что Турция и Иран были первыми государствами, признавшими независимость Грузии, Армении и Азербайджана и еще в 1991 году объявили о готовности установить с этими странами дипломатические отношения. Последующий период, насыщенный дипломатическими интригами и драматическими событиями (среди которых особо выделяется карабахский конфликт и августовские события 2008 года вокруг Южной Oceтии) несомненно, привел стороны, к усилению региональных позиций наследников Блистательной Порты и Персидской империи. С другой стороны, активное вовлечение в региональные процессы Сoединенных Штатов и Европейского Союза поставил перед Анкарой и особенно перед Тегераном новые вызовы, побуждая их к осмотрительности и нахождению точек соприкосновения с Россией, которая после десятилетия хаоса и политической невнятицы вновь осознает стратегическую важность Кавказа для судеб собственной государственности ${ }^{10}$.

Интересы всех трех государств тесным образом переплетаются, будучи объектом воздействия третьих сил, накладывающих существенные ограничители на пределы взаимодействия ${ }^{11}$. Что касается Турции, то лидеры этой страны проводят активную многовекторную политику в лучших традициях «кемализма», отдельные аспекты которого являются в современной Турции предметом общественных дискуссий ${ }^{12}$. Первоначальные амбиции в отношении Кавказа сменились более трезвым осознанием пределов собственных возможностей. Турция позиционируется в качестве ключевого игрока и самостоятельного силового полюса, пытаясь таким образом выжать максимум возможного из различных формальных и неформальных союзов

\footnotetext{
${ }^{9}$ Андрей Арешев, Россия, Турция и Иран на Южном Кавказе: Соперничество или партнерство, выступления автора в ходе научного семинара «Социально-политические и культурные процессы в современной России» (Ереван, 23 ноября 2010 г.)

10 Петросян Д. Иран заинтересован в сохранении статускво на Южном Кавказе // Ноев Ковчег. - 2010. - № 11; Iran opposes any US peacekeeping role for Karabakh // Hurriyet. 2010 - 24 June.

${ }^{11}$ Андрей Арешев, Россия, Турция и Иран на Южном Кавказе: Соперничество или партнерство, выступления автора в ходе научного семинара «Социально-политические и культурные процессы в современной России» (Ереван, 23 ноября 2010 г.)

${ }^{12}$ Özdemir İnce, Tahrir Meydanı Kemalizm'e karşı, 12.02.2011, www.hurriyet.com.tr
} 


\section{Политика и общество $1(97) \cdot 2013$}

- как тех, в которых Турция состоит, так и в тех, которые пытается формировать.

Представляется, что Турция и далее будет стараться совместить в максимально возможных пределах сохранение отношений с США, интеграцию в ЕС, а также развития «ближневосточного» (арабские страны) и «евразийского» вектора своей внешней политики, частью которого являются Россия и Иран ${ }^{13}$.

Несмотря на периодически возобновляемую антиизраильскую и антиамериканскую риторику, представляется, что полномасштабная ссора с США и НАТО не является перспективным направлением внешней политики Анкары ${ }^{14}$. Турция достаточно плотно интегрирована в структуры Альянса ${ }^{15}$. Участие Турции в некоторых операциях НАТО оказывает неоднозначное влияние на ее формирующуюся самостоятельную региональную политику, однако надо полагать, что стороны намерены вырабатывать здесь взаимоприемлемые решения в рамках наработанного ими в течение многих десятилетий формальных и неформальных консультаций ${ }^{16}$. Например, предлагаемая НАТО идея создания единого противоракетного щита способна если не разрушить, то, по крайней мере, поставить под серьезное сомнение турецкоиранское сближение, о котором в последнее время очень много говорили. Заместитель помощника министра обороны США по вопросам Европы и НАТО Джеймс Таунсенд заявлял, что Турция «в значительной степени находится на передовой линии» потенциального конфликта с использованием баллистических ракет ${ }^{17}$. Премьер-министр Турции заявляет, что соответствующее решение, без сомнения, должно быть принято с позиций членства в НАТО. С другой стороны, Турция пытается посредничать между Тегераном и Брюсселем, позиционируя себя в качестве ключевого игрока на Ближнем Востоке ${ }^{18}$.

\footnotetext{
${ }^{13}$ Александр Васильев, Институт востоковедения РАН, Черноморский регион во внешнеполитических концепциях Турции: Россия и Турция на Черном море, 19.03.2011

14 Андрей Арешев, Турция, Иран и Россия в Закавказье, 26.11.2010, http://www.fondsk.ru/pview/2010/11/26/turcijairan-i-rossija-v-zakavkaze.html

15 Турция является членом НАТО с 1952 года.

${ }^{16}$ Sinan Oğan, The Frame of Turkey's Regional Security Efforts in the Caucasus Cooperation and Stability Platformhttp://www. turksam.org/tr/

${ }^{17}$ Там же.

${ }^{18}$ Там же.
}

В отношениях с Россией Турция будет преследовать прежде всего собственные цели и интересы. По мнению А. Давутоглу, внешняя политика Турции позволит ей увеличить свое геополитическое значение и влияние в стратегически важных для турецкого государства зонах, входящих, по его мнению, в «ближнее сухопутное и морское пространство» Турции ${ }^{19}$.

Стержнем российско-турецкого сотрудничества является энергетика и туризм. По-прежнему не решена проблема диверсификации двусторонних связей в направлении машиностроения и высокотехнологичных отраслей. Несколько обостряя предлагаемый тезис, можно сказать, что Турция извлекает из сотрудничества с Россией максимум пользы (энергетика, ВТС), в то время как для Москвы оно носит в известной мере вынужденный характер ${ }^{20}$. Согласно некоторым оценкам, поддержка Россией газопроводного проекта Самсун - Джейхан стала в свое время для России скорее вынужденным шагом в обмен на согласие Анкары провести геологоразведочные работы в зоне возможного прохождения газопровода «Южный поток» ${ }^{21}$. Амбициозные экономические проекты могут попасть в очевидную зависимость от воли Анкары и Киева, которая, как мы понимаем, может оказаться весьма переменчивой.

И Москва, и Тегеран продолжают оказывать немалое влияние и на урегулирование региональных конфликтов, и на ситуацию на Каспии, и на политическую и экономическую жизнь государств Южного Кавказа (особенно Азербайджана и Армении) 22 . Новая тактика Анкары заключается в сближении с Россией и Ираном. Так, если в 1994 году начальник генерального штаба Турции Д.Гюреш заявлял, что «Россия стала весьма серьезной угрозой для Турции» ${ }^{23}$, большей, по его словам, чем после войны, то в 2010 году Россия, Армения, Грузия, Иран, а также Сирия, Болгария

\footnotetext{
${ }^{19}$ Ahmet Davutoğlu, Stratejik derinlik: Türkiye'nin Uluslararası Konumu, Istanbul, 2009, .- 584;

20 Сварани А. Основные угрозы интересам Российской Федерации от идеологии и политики пантюркизма (внешние и внутренние аспекты) // Регион и мир (Ереван). - 2010. - № 1. - с. 11

${ }^{21}$ Турецкий выбор России Самсун - Джейхан сулит России целый ряд геополитических выгод, 30.03.2010, http://www. indpg.ru

${ }^{22}$ Безопасность на Южном Кавказе: каково влияние России? 24.02.2011, http://www.casfactor.com

${ }^{23}$ Дмитрий Тренин, Анкара-Москва: Сотрудничество, игра-
} ющее на Баку, 11.05.2011 
Конфликт и консенсус

и Греция были исключены из списка угроз турецкому государству, перечисляемых в руководящих документах в сфере национальной безопасности ${ }^{24}$. Совершенно очевидно, что сделано это было после дательного анализа не только внешнеполитической динамики, но и военного потенциала турецкой армии в сравнении, по крайней мере, с армиями некоторых из вышеперечисленных государств.

В целом политика Турции на Кавказском направлении, несмотря на динамизм и активность, будет сдерживаться рядом ограничителей, связанных с необходимостью тем или иным образом координировать предпринимаемые шаги с другими акторами, реализующими свои национальные интересы в кавказском регионе ${ }^{25}$. На среднесрочную перспективу в армяно-турецких отношениях вряд ли стоит ожидать прорыва ${ }^{26}$. Совместная деятельность России и Турции в деле урегулирования имеющихся здесь региональных конфликтов могла бы принести пользу, однако она предполагает высокий уровень взаимного доверия. Здесь можно вспомнить высказывавшееся на уровне российского политического руководства отношение к увязке процесса нормализации армяно-турецких отношений с урегулированием нагорно-карабахского конфликта. В то же время, в случае дальнейшего ухудшения отношений Анкары с Вашингтоном и особенно с Израилем как внутри, так и вовне Турции могут появиться дополнительные факторы, препятствующие ее позиционированию в качестве самостоятельного регионального центра силы ${ }^{27}$.

Обобщая, необходимо отметить: несмотря на наличие целого ряда задач, которые Россия и Турция могут решать в формате «многопланового партнерства», в будущем их разногласия относительно различных аспектов мировой и региональной политики вполне вероятны и скорее всего даже неизбежны.

На динамику российско-иранских отношений также серьезное влияние оказывают третьи страны. Включение афганской проблематики в повестку дня «перезагрузки» российско-американских отно-

\footnotetext{
${ }^{24}$ А.Арешев, «Турция, Иран и Россия в Закавказье», 2010, http://www.fondsk.ru/pview/2010/11/26/turcija-iran-i-rossija-vzakavkaze.html

${ }^{25}$ www.mfa.gov.tr

${ }^{26}$ Маргарита Саканян, Новый треугольник влияния в Закавказье - «Москва-Ереван-Анкара», 2.09.2009

${ }^{27}$ Ahmet Davutoğlu, Stratejik derinlik: Türkiye'nin Uluslararas1 Konumu, Istanbul, 2005, page-36.
}

шений стало проявлением высокого дипломатического искусства новой американской администрации (аналогично включению «афганского вопроса» в актуальную повестку внешнеполитического диалога между Вашингтоном и Дели). Таким образом, Соединённым Штатам удалось нанести ущерб отношениям Ирана с его главными региональными партнёрами - Россией и Индией. Крупные контракты на поставку современных видов вооружения Саудовской Аравии призваны изолировать Иран и на Ближнем Востоке ${ }^{28}$. Активизацию Тегерана на южнокавказском направлении следует рассматривать в более широком контексте региональных процессов на Ближнем и Среднем Востоке 29 .

В исследовательской литературе, посвященной взаимоотношениям государств Южного Кавказа, а также возможным региональным форматам безопасности, «иранский фактор» нередко недооценивается, что, как представляется, вряд ли разумно в контексте незавершенности геополитического позиционирования региона, его места в формирующейся архитектуре региональной и мировой безопасности ${ }^{30}$. Интерес Тегерана к Кавказу и Центральной Азии обуславливается едва ли не единственным фактором, а именно - стремлением вырваться из международной изоляции, куда он попал волею западных держав во главе с США. Если это и верно, то только отчасти. Иранские исследователи неизменно, в той или иной форме, подчеркивают, что эта страна имеет много общего со своими соседями, будь то в историческом, культурном или лингвистическом плане; поэтому, несмотря на многие различия, существует и много возможностей для взаимопонимания, которые в Иране намерены использовать в полной мере. Интересы Тегерана на Кавказе вступают в соприкосновение с интересами России и Турции, и представляется, что говорить о полном взаимопонимании явно преждевременно $^{31}$. Достаточно вспомнить реакцию Ирана на слухи о размещении в нахичеванской автономии турецкой военной базы, или недвусмысленное замеча-

\footnotetext{
${ }^{28}$ Cengiz Çandarın yazısı. Radikal. 1 Haziran 2010

${ }^{29}$ Там же.

${ }^{30}$ Нахаванди Ф. Россия, Иран и Азербайджан. Исторические истоки внешней политики Ирана // http://poli.vub.ac.be/publi/ ContBorders/rus/ch0601.htm

${ }^{31}$ Нахаванди Ф. Россия, Иран и Азербайджан. Исторические истоки внешней политики Ирана // http://poli.vub.ac.be/publi/ ContBorders/rus/ch0601.htm
} 


\section{Политика и общество $1(97) \cdot 2013$}

ние о том, что у Тегерана имеется собственное представление о том, каким должен быть национальный состав возможного миротворческого контингента в зоне карабахского конфликта ${ }^{32}$.

Российско-иранские отношения стали все чаще рассматриваться с позиции национальной выгоды и интересов. В этом случае, поведение двух стран, периодически сближающихся или отдаляющихся друг от друга, зависит от национальных интересов, и что немаловажно, от путей, которые, по мнению тех или иных групп, ведут к наиболее эффективной реализации этих национальных интересов.

Геополитическое единство кавказского региона сомнению практически не подвергается. На протяжении последних 20 лет позиция Ирана относительно чеченского конфликта, экспансии радикального исламизма была весьма сдержанной. Сейчас в некоторых иранских публикациях можно встретить мнение о том, что эта страна, в случае выбора ею удачной стратегии, может использовать свое геополитического положение и влияние в исламском мире с тем, чтобы равноправно соревноваться и сотрудничать с Россией ${ }^{33}$. Высказываются мнения, что это «новое «статус-кво» освободит Тегеран от необходимости выслушивать отговорки Москвы по самым разным вопросам, касающимся не только двустороннего сотрудничества, но и региональных и глобальных проблем» ${ }^{34}$.

Ситуация на Южном Кавказе в значительной мере определяется динамикой взаимоотношений в «треугольнике» Москва - Анкара - Тегеран, при обязательном учете внешнего «контура», включающего отношения каждой из этих стран, прежде всего, с Соединенными Штатами, Европейским Союзом и некоторыми ключевыми странами НАТО. Это, с одной стороны, предопределяет объективную заинтересованность в недопущении крупномасштабных конфликтов, способных негативно повлиять на региональный баланс сил, рост экономического сотрудничества, реализацию трансграничных проектов; с другой, свидетельствует о наличии серьезных

\footnotetext{
${ }^{32}$ См.: Агаджанян М. Роль России и Ирана в урегулировании карабахского конфликта // Регион и мир (Ереван). - 2010. № $1 .-$ c. 58

${ }^{33}$ Iranian Approaches to the Nagorno Karabakh Problem // http:// www.turksam.org/en/a255.html

${ }^{34}$ А.Г. Арешев, «Россия, Турция и Иран на Южном Кавказе: Соперничество или партнерство», 23 ноября 2010
}

факторов дестабилизации, прежде всего связанных с возможными планами военных действий против Ирана, которые способны привести к самым непредсказуемым последствиям ${ }^{35}$.

\section{Библиография:}

1. http://ethnomir.ru/ethno/caucasus

2. KavkazWeb.net - Главный интернет портал Кавказа

3. Закавказье и сопредельные страны в период эллинизма./История Древнего мира. Расцвет Древних обществ.- М.:Знание, 1983 - с.399-414

4. www.abp.am>armenia/geo

5. http://ru.wikipedia.org/wiki/A3ep6aitfl $>\mathrm{KaH}$

6. Кац М. Геополитика Азербайджана/ Кац М. // United Press International.- США .-2006.-22 августа

7. Арешев А., Турция, Иран и Россия в Закавказье, 26.11.2010

8. Арешев А., Россия, Турция и Иран на Южном Кавказе: Соперничество или партнерство, выступления автора в ходе научного семинара «Социально-политические и культурные процессы в современной России» (Ереван, 23 ноября 2010 г.)

9. Петросян Д. Иран заинтересован в сохранении статус-кво на Южном Кавказе // Ноев Ковчег. 2010. - № 11; Iran opposes any US peacekeeping role for Karabakh // Hurriyet. - 2010 - 24 June.

10. Арешев А., Россия, Турция и Иран на Южном Кавказе: Соперничество или партнерство, выступления автора в ходе научного семинара «Социально-политические и культурные процессы в современной России» (Ереван, 23 ноября 2010 г.)

11. Özdemir İnce, Tahrir Meydanı Kemalizm'e karşı, 12.02.2011, www.hurriyet.com.tr

12. Александр Васильев, Институт востоковедения РАН, Черноморский регион во внешнеполитических концепциях Турции: Россия и Турция на Черном море, 19.03.2011

13. Арешев А., Турция, Иран и Россия в Закавказье, 26.11.2010, http://www.fondsk.ru/pview/2010/11/26/ turcija-iran-i-rossija-v-zakavkaze.html.

14. Sinan Oğan, The Frame of Turkey's Regional Security Efforts in the Caucasus Cooperation and Stability Platformhttp://www.turksam.org/tr/

\footnotetext{
${ }^{35}$ Нахаванди Ф. Россия, Иран и Азербайджан. Исторические истоки внешней политики Ирана // http://poli.vub.ac.be/publi/ ContBorders/rus/ch0601.htm
} 
Конфликт и консенсус

15. Ahmet Davutoğlu, Stratejik derinlik: Türkiye'nin Uluslararası Konumu, Istanbul, 2009, .- 584

16. Сваранц А. Основные угрозы интересам Российской Федерации от идеологии и политики пантюркизма (внешние и внутренние аспекты) // Peгион и мир (Ереван). - 2010. - № 1. - с. 11

17. Турецкий выбор России Самсун - Джейхан сулит России целый ряд геополитических выгод, 30.03.2010, http://www.indpg.ru

18. Безопасность на Южном Кавказе: каково влияние России? 24.02.2011, http://www.casfactor.com

19. Тренин Д., Анкара-Москва: Сотрудничество, играющее на Баку, 11.05.2011

20. Арешев А., «Турция, Иран и Россия в Закавказье», 2010, http:/www.fondsk.ru/pview/2010/11/26/ turcija-iran-i-rossija-v-zakavkaze.html

21. www.mfa.gov.tr

22. Саканян М., Новый треугольник влияния в Закавказье - «Москва-Ереван-Анкара», 2.09.2009

23. Ahmet Davutoğlu, Stratejik derinlik: Türkiye'nin Uluslararası Konumu, Istanbul, 2005, page-36.

24. Cengiz Çandarın yazısı. Radikal. 1 Haziran 2010

25. Нахаванди Ф. Россия, Иран и Азербайджан. Исторические истоки внешней политики Ирана // http://poli.vub.ac.be/publi/ContBorders/rus/ ch0601.htm

26. Нахаванди Ф. Россия, Иран и Азербайджан. Исторические истоки внешней политики Ирана // http:// poli.vub.ac.be/publi/ContBorders/rus/ch0601.htm

27. Агаджанян М. Роль России и Ирана в урегулировании карабахского конфликта // Регион и мир (Ереван). - 2010. - № 1. - с. 58

28. Iranian Approaches to the Nagorno Karabakh Problem // http://www.turksam.org/en/a255.html

29. Арешев А.Г., Россия, Турция и Иран на Южном Кавказе: Соперничество или партнерство, 23 ноября 2010

30. Нахаванди Ф. Россия, Иран и Азербайджан. Исторические истоки внешней политики Ирана // http:// poli.vub.ac.be/publi/ContBorders/rus/ch0601.htm

\section{References (transliteration):}

1. Zakavkaz'e i sopredel'nye strany v period ellinizma./Istoriya Drevnego mira. Rastsvet Drevnikh obshchestv.- M.:Znanie, 1983 - s.399-414

2. Kats M. Geopolitika Azerbaydzhana/ Kats M. //United Press International.- SShA .-2006.-22 avgusta
3. Areshev A., Turtsiya, Iran i Rossiya v Zakavkaz'e, 26.11.2010

4. Areshev A., Rossiya, Turtsiya i Iran na Yuzhnom Kavkaze: Sopernichestvo ili partnerstvo, vystupleniya avtora v khode nauchnogo seminara «Sotsial'nopoliticheskie i kul'turnye protsessy v sovremennoy Rossii» (Erevan, 23 noyabrya 2010 g.)

5. Petrosyan D. Iran zainteresovan v sokhranenii statuskvo na Yuzhnom Kavkaze // Noev Kovcheg. - 2010. - № 11; Iran opposes any US peacekeeping role for Karabakh // Hurriyet. - 2010 - 24 June.

6. Areshev A., Rossiya, Turtsiya i Iran na Yuzhnom Kavkaze: Sopernichestvo ili partnerstvo, vystupleniya avtora v khode nauchnogo seminara «Sotsial'nopoliticheskie i kul'turnye protsessy v sovremennoy Rossii» (Erevan, 23 noyabrya 2010 g.)

7. Özdemir İnce, Tahrir Meydanı Kemalizm'e karşı, 12.02.2011, www.hurriyet.com.tr

8. Aleksandr Vasil'ev, Institut vostokovedeniya RAN, Chernomorskiy region vo vneshnepoliticheskikh kontseptsiyakh Turtsii: Rossiya i Turtsiya na Chernom more, 19.03.2011

9. Areshev A., Turtsiya, Iran i Rossiya v Zakavkaz'e, 26.11.2010,http://www.fondsk.ru/pview/2010/11/26/ turcija-iran-i-rossija-v-zakavkaze.html.

10. Sinan Oğan, The Frame of Turkey's Regional Security Efforts in the Caucasus Cooperation and Stability Platformhttp://www.turksam.org/tr/

11. Ahmet Davutoğlu, Stratejik derinlik: Türkiye'nin Uluslararası Konumu, Istanbul, 2009, .- 584;

12. Svarants A. Osnovnye ugrozy interesam Rossiyskoy Federatsii ot ideologii i politiki pantyurkizma (vneshnie i vnutrennie aspekty) // Region i mir (Erevan). 2010. - № 1. - s. 11

13. Turetskiy vybor Rossii Samsun - Dzheykhan sulit Rossii tselyy ryad geopoliticheskikh vygod, 30.03.2010, http://www.indpg.ru

14. Bezopasnost' na Yuzhnom Kavkaze: kakovo vliyanie Rossii? 24.02.2011, http://www.casfactor.com

15. Trenin D., Ankara-Moskva: Sotrudnichestvo, igrayushchee na Baku, 11.05.2011

16. Areshev A., «Turtsiya, Iran i Rossiya v Zakavkaz'e», 2010, http://www.fondsk.ru/pview/2010/11/26/turcija-iran-i-rossija-v-zakavkaze.html

17. Sakanyan M., Novyy treugol'nik vliyaniya v Zakavkaz'e - «Moskva-Erevan-Ankara», 2.09.2009

18. Ahmet Davutoğlu, Stratejik derinlik: Türkiye'nin Uluslararası Konumu, Istanbul, 2005, page-36.

19. Cengiz Çandarın yazısı. Radikal. 1 Haziran 2010 


\section{Политика и общество 1 (97) • 2013}

20. Nakhavandi F. Rossiya, Iran i Azerbaydzhan. Istoricheskie istoki vneshney politiki Irana // http:// poli.vub.ac.be/publi/ContBorders/rus/ch0601.htm

21. Nakhavandi F. Rossiya, Iran i Azerbaydzhan. Istoricheskie istoki vneshney politiki Irana // http:// poli.vub.ac.be/publi/ContBorders/rus/ch0601.htm

22. Agadzhanyan M. Rol' Rossii i Irana v uregulirovanii karabakhskogo konflikta // Region i mir (Erevan). 2010. - № 1. - s. 58
23. Iranian Approaches to the Nagorno Karabakh Problem // http://www.turksam.org/en/a255.html

24. Areshev A.G., Rossiya, Turtsiya i Iran na Yuzhnom Kavkaze: Sopernichestvo ili partnerstvo, 23 noyabrya 2010

25. Nakhavandi F. Rossiya, Iran i Azerbaydzhan. Istoricheskie istoki vneshney politiki Irana // http://poli.vub.ac.be/publi/ContBorders/rus/ ch0601.htm 